\title{
Experimental and Numerical Studies on Residual Stress in Wide Butt Welds
}

\author{
Yang Ding, ${ }^{1,2}$ Zhe Liu, ${ }^{1,2}$ Jia-Bao Yan, ${ }^{1,2}$ and Liang Zong ${ }^{1,2}$ \\ ${ }^{1}$ Department of Civil Engineering, Tianjin University, Tianjin 300072, China \\ ${ }^{2}$ Key Laboratory of Coast Civil Structure Safety, Ministry of Education, Tianjin University, Tianjin 300072, China
}

Correspondence should be addressed to Jia-Bao Yan; ceeyanj@163.com

Received 2 August 2016; Revised 23 November 2016; Accepted 25 December 2016; Published 15 January 2017

Academic Editor: Antti Salminen

Copyright (C) 2017 Yang Ding et al. This is an open access article distributed under the Creative Commons Attribution License, which permits unrestricted use, distribution, and reproduction in any medium, provided the original work is properly cited.

The presence of residual stress in steel members can significantly compromise the stiffness and fatigue life of steel structural components. This influence becomes more serious for the wide butt welds in the construction of large-sized steel members due to the different residual stress distribution from the normal size butt welds. This paper experimentally studied the residual stress in the wide butt welds through an 8-experiment test program. High residual stress was produced during the wide butt welding and this stress was observed to be even higher than the yield strength of the steel. Moreover, this residual stress in the steel plate was firstly compressive and then transferred into tensile stress with the increase in the distance away from the butt weld line. The magnitude of the residual stress increased with the increase in the width of the welding seams. This paper also developed a finite element model by SYSWELD to simulate the residual stress produced by the wide butt welding. The accuracy of the FE simulation was checked by the reported test results. In order to reduce the residual stress, the ultrasonic peening method was adopted. The analysis results indicated that ultrasonic peening method effectively reduced the residual stress caused by the wide butt welding during the construction.

\section{Introduction}

The Whitewater River Bridge in Shandong Province, China, is a continuous steel truss girder bridge with four spans of $45+50+50+45 \mathrm{~m}$. In order to increase the construction efficiency, the girders were prefabricated in the factory and then assembled on site by welding (Figure 1). However, the residual stress produced during the welding process might reduce the ultimate load carrying capacity of the members due to the degradation of stiffness and untimely yielding as well as the fatigue endurance of these members under cyclic or dynamic loading [1].

As specified in the design codes [2, 3], the width of the butt welding should be controlled within $10 \mathrm{~mm}$. Sometimes, the width of these welding seams was not well controlled and usually larger than $10 \mathrm{~mm}$ (Figure 2), thus forming wide butt welding.

Previous studies mainly focused on the assessment of the residual stress of normal welding seams in buildings, automotive engineering, and offshore pipelines [4]. Zhou et al. [5] used the blind-hole method to measure the residual stress of the integral hybrid section of steel members in Wuhu Yangtze River Bridge. However, there were limited measuring points and the distribution of these measuring points was not well organized. Tian and Li [6] proposed a new testing method based on the yield stiffness principle to measure the residual stress. However, this method could be used only in the laboratory condition, and technical improvements were still required for the site application. Wang [7] studied the residual stress in medium thick steel plate and improved the measurement accuracy of the residual stress. Huang et al. [8] carried out a full-scale experiment on the integral hybrid of Dong River Bridge to obtain the distribution of the residual stress on the cross section. Wang et al. [9] developed the residual stress model of Q690 $\mathrm{H}$-section and BOX-section. However, the developed model can be only used in the normal welding seams. Wang et al. [10] compared the section method and the hole-drilling method in the measurement of 


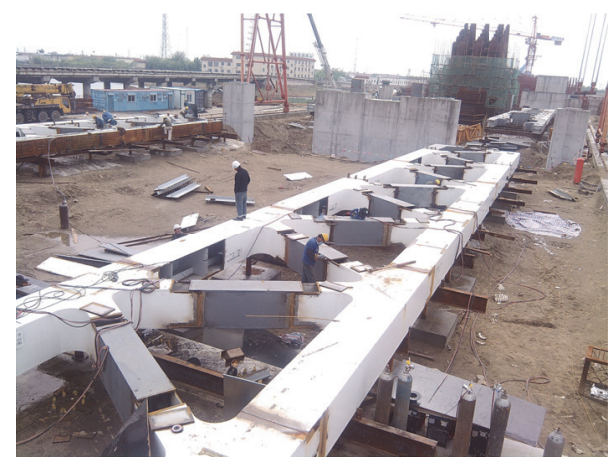

FIGURE 1: Steel truss girders in the bridge.

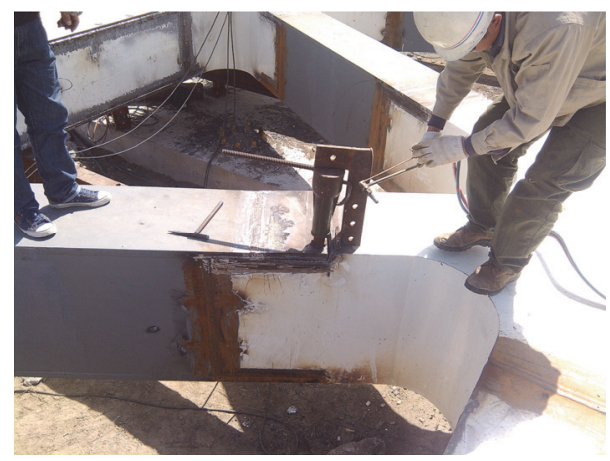

FIGURE 2: Gap due to installation errors.

the residual stress. Although this method was more accurate, it was not suitable for the measurement in the construction site.

The residual stress of wide butt welding was seldom investigated. Therefore, it is important to measure the residual stress in a construction plant. The distribution of residual stress in wide butt welding should be explored for the purpose of minimizing the residual stress in the construction of girders and steel members.

This paper mainly focused on the assessment of the residual stress produced by wide butt welding. In order to investigate the distribution of the residual stress, eight butt welds in the steel truss bridge were chosen for the tests. Followed, the blind hole-drilling method was adopted to measure the residual stress during the construction. Finite element model of these wide butt welds was also developed to simulate the welding process. Finally, the ultrasonic peening method was used to minimize the residual stress and the performance of the ultrasonic peening method was evaluated. Finally, based on these experimental results, some construction advices such as the reductions of residual stress were proposed.

\section{Experimental Studies on Residual Stress in Wide Butt Welds}

2.1. Wide Butt Welds and Measurements. Eight butt welds of the steel truss bridge were chosen in the experiment and four of these welding seams were processed by ultrasonic peening. The typical width of the common welds on the surface was usually smaller than $45 \mathrm{~mm}$. However the width of representative wide butt welding seams observed in the construction site ranged from $45 \mathrm{~mm}$ to $75 \mathrm{~mm}$. The selected widths for wide butt welds were $45 \mathrm{~mm}, 55 \mathrm{~mm}, 65 \mathrm{~mm}$, and $75 \mathrm{~mm}$, respectively (Figure 3). Meanwhile, in order to guarantee the accuracy of the measurements, all the selected welding seams were on the top flat surface of the box girders.

The hole-drilling may redistribute the residual stress. If the distance between the two drilling holes is too short, this influence tends to be more significant. It is important to properly arrange the locations among these measuring locations. Pei et al. [11] pointed out that the shortest distance between two measuring locations should be more than 15 times the hole diameter. Thus, in this test program, the hole diameter was $2.5 \mathrm{~mm}$ and the distance between two neighboring holes along $Y$-direction was $40 \mathrm{~mm}$. Meanwhile, the distance between two neighboring holes along $X$-direction was $175 \mathrm{~mm}$. In order to depict the distribution of residual stress, nine locations were arranged for each welding seam (Figure 4).

2.2. Mechanical Properties of the Steel Materials and Welds. The steel truss in the bridge was fabricated with the Q345qD type of steel and E501T-1 type of weld rod was chosen for the welding. The properties of these steels and weld rods were obtained from tensile test on the steel coupons according to ASTM A370-13 [12]. Table 1 lists the mechanical properties of these steels and weld rods obtained from the tensile test.

2.3. Blind Hole-Drilling Method for the Measurement of the Residual Stress. The blind hole-drilling method is characterized by the small-diameter drilling, the small damage to the components, and the reliable measurements, and it has become a standard method for construction site measurements. Measuring points for the hole-drilling method were marked at the locations based on the consideration of each surface of the steel truss hole-drilling regions (Figure 5). Before fixing the strain gage rosettes, the regions should be polished by gauze rounds. Strain gage rosettes were fixed with rapid gel. The recommended diameter and depth of the drilled hole were, respectively, $2.5 \mathrm{~mm}$ and $2 \mathrm{~mm}$. Once the centers of the hole and the strain gage circle coincided with each other, a hole was drilled with the electric hand-drill. The removement of the materials from the surface of the specimen caused the redistribution of encased residual stress. The machining-induced residual strain was subtracted from the relieved strain. It was measured by strain gage to obtain the purely relieved strain. The purely relieved strains in the plane can be represented with residual stress based on

$$
\begin{gathered}
\sigma_{x}=E \cdot \frac{B\left(\varepsilon_{x}+\varepsilon_{y}\right)+A\left(\varepsilon_{x}-\varepsilon_{y}\right)}{4 A B}-\sigma_{d}, \\
\sigma_{y}=E \cdot \frac{B\left(\varepsilon_{x}+\varepsilon_{y}\right)-A\left(\varepsilon_{x}-\varepsilon_{y}\right)}{4 A B}-\sigma_{d},
\end{gathered}
$$



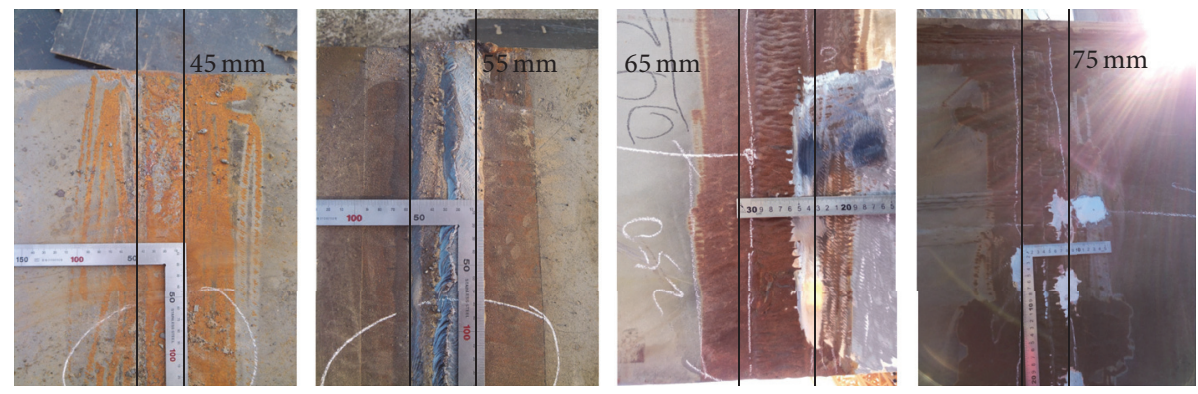

FIGURE 3: Selected welding seams with different widths.

TABLE 1: Material properties.

\begin{tabular}{lccccc}
\hline Materials & $E_{s}(\mathrm{GPa})$ & $\varepsilon_{u}$ & $f_{y}(\mathrm{MPa})$ & $f_{u}(\mathrm{MPa})$ & 553 \\
\hline Q345qD & 211 & 0.13 & 430 & 550 & 25 \\
Q345qD & 216 & 0.14 & 435 & 539 & 22 \\
Q345qD & 214 & 0.13 & 420 & 546 & 25 \\
E501T-1 & 223 & 0.15 & 464 & 546 \\
\hline
\end{tabular}

Notes: $f_{y}$ denotes the yield strength of steel plates; $f_{u}$ denotes the ultimate tensile stress; $\varepsilon_{u}$ is the strain corresponding to $f_{u} ; E_{s}$ is Young's modulus; $\Delta \%$ is the percentage of elongation after fracture.

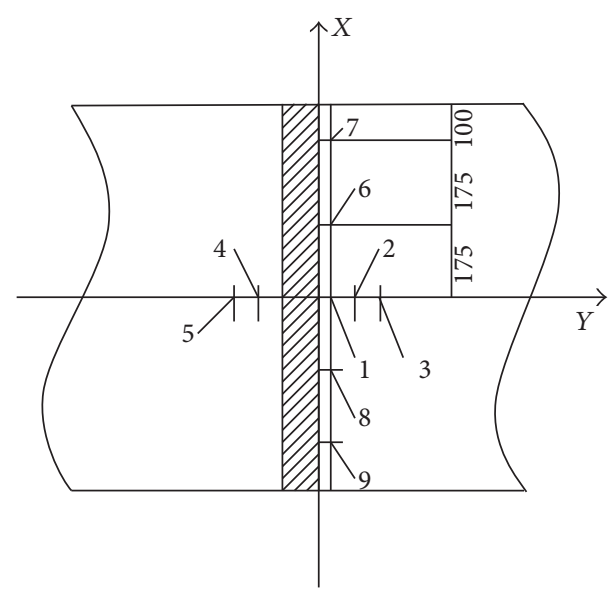

Figure 4: Arrangement of the testing points.

where $\sigma_{x}$ is the longitudinal residual stress; $\sigma_{y}$ is the transversal residual stress; $\varepsilon_{x}$ and $\varepsilon_{y}$ are, respectively, the longitudinal strain and transversal strain; $A$ and $B$ represent the calibration constants which indicate the relieved strains due to the unit stress within the hole depth; $\sigma_{d}$ is the residual stress induced by the machining load and other loads. We adopted the previously reported stress level $[13,14]$ as the calibration constants $A$ and $B$ for rosette TJ120-1.5- $\varphi 1.5$. The residual surface stress $\sigma_{d}$ induced by the polishing procedure was measured by ZRIME with the hole-drilling method and its recommended mean value was $-22.1 \mathrm{MPa}$.

\section{Testing Results}

3.1. Residual Stress before Ultrasonic Peening. Table 2 lists the measured residual stress of different welding seams. The

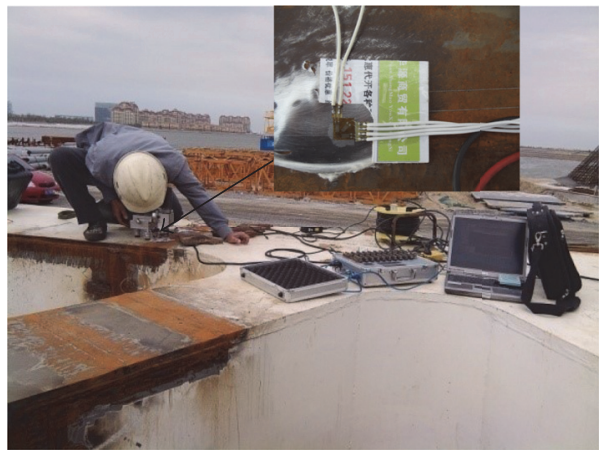

FIGURE 5: Hole-drilling method.

distributions of residual stress along welding seams with different widths $(45 \mathrm{~mm}, 55 \mathrm{~mm}, 65 \mathrm{~mm}$, and $75 \mathrm{~mm}$ ) are shown in Figures 6 and 7. The residual stress usually has two components: the residual stress along the direction of welding seam and the residual stress perpendicular to the direction of welding seam. Figures 6 and 7 show the longitudinal and the transversal residual stress, respectively.

3.2. Discussions. From the results of these welds, the maximum longitudinal residual stress was $341.5 \mathrm{MPa}$. Almost the maximum value was at location 1 , which was near the melting area of welding seam. The residual stress was approximately equably along the $X$-direction. However, along the $Y$-direction the residual stress was obviously varied. The residual stress became lower with the increasing distance from the weld.

The obtained residual stress was used to check the equilibrium condition for the whole sections. Theoretically, since there are no external forces applied to the cross 

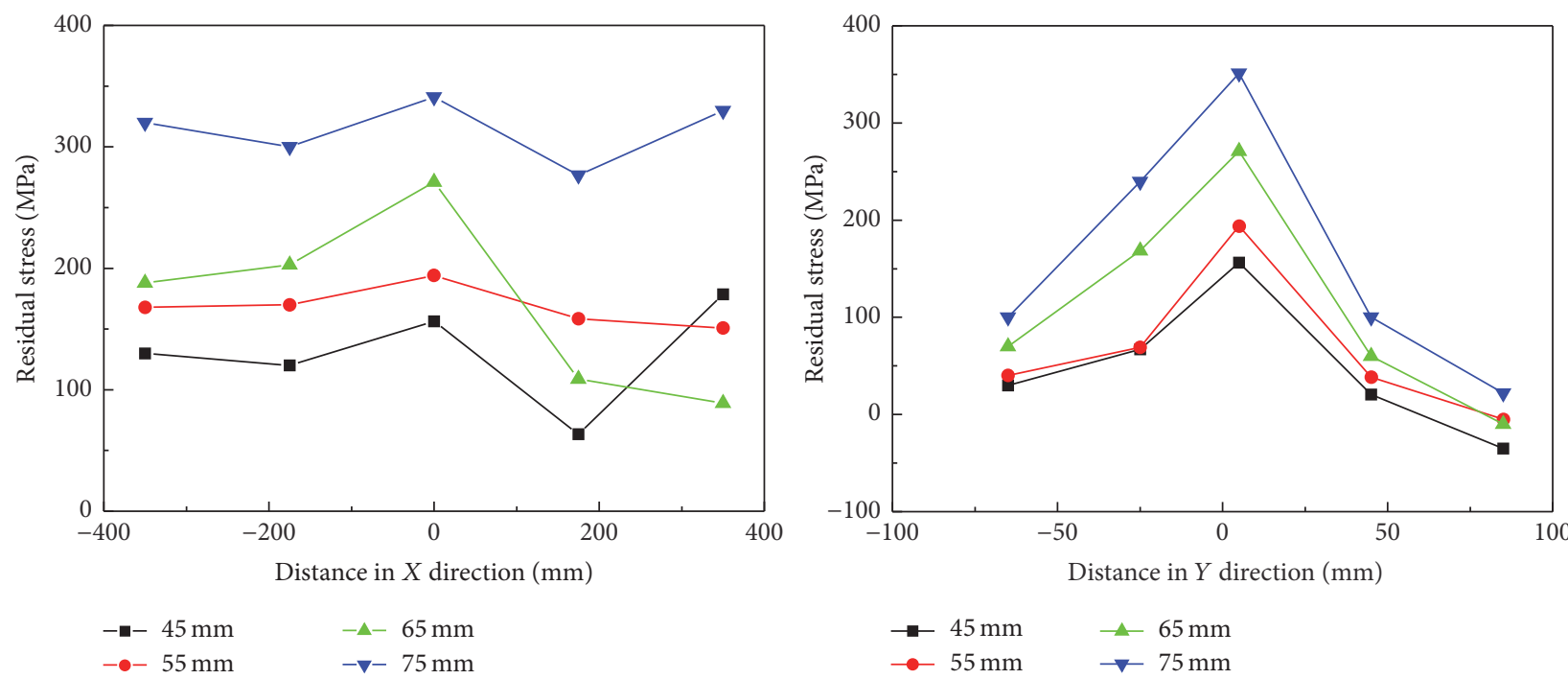

FIGURE 6: Longitudinal residual stress.
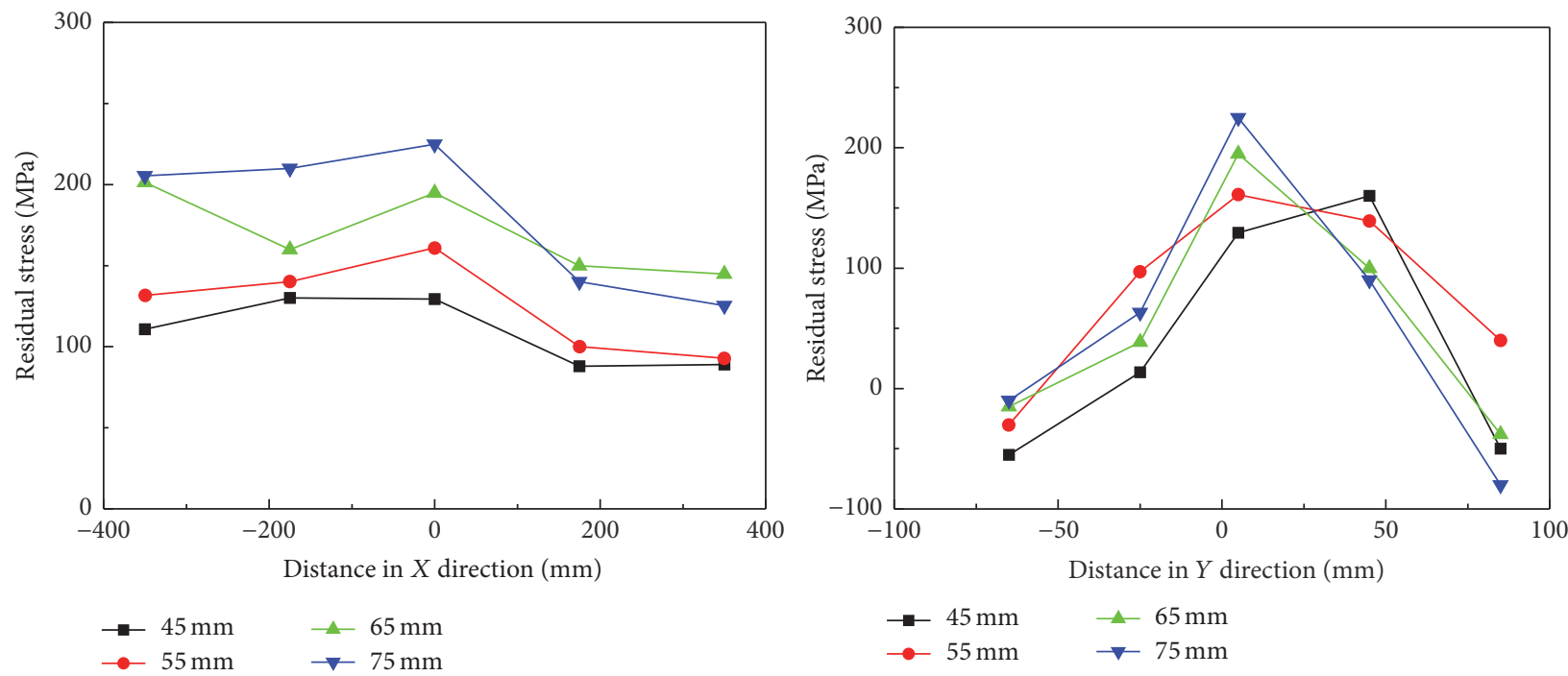

FIGURE 7: Transversal residual stress.

TABLE 2: Results of the measured residual stress.

\begin{tabular}{|c|c|c|c|c|c|c|c|c|}
\hline \multirow[t]{2}{*}{ Points } & \multicolumn{2}{|c|}{$\begin{array}{l}\text { Residual stress of } 45 \mathrm{~mm} \text { width } \\
\qquad(\mathrm{MPa})\end{array}$} & \multicolumn{2}{|c|}{$\begin{array}{l}\text { Residual stress of } 55 \mathrm{~mm} \\
\text { width }(\mathrm{MPa})\end{array}$} & \multicolumn{2}{|c|}{$\begin{array}{l}\text { Residual stress of } 65 \mathrm{~mm} \\
\text { width }(\mathrm{MPa})\end{array}$} & \multicolumn{2}{|c|}{$\begin{array}{c}\text { Residual stress of } 75 \mathrm{~mm} \\
\text { width }(\mathrm{MPa})\end{array}$} \\
\hline & $\sigma_{x}$ & $\sigma_{y}$ & $\sigma_{x}$ & $\sigma_{y}$ & $\sigma_{x}$ & $\sigma_{y}$ & $\sigma_{x}$ & $\sigma_{y}$ \\
\hline 1 & 156.4 & 129.3 & 194.1 & 161.5 & 271.1 & 194.9 & 341.5 & 224.8 \\
\hline 2 & 20.7 & 160.6 & 38.5 & 139.3 & 60.1 & 100.2 & 102.6 & 90.9 \\
\hline 3 & -35.1 & -49.9 & -5.9 & 40.2 & -10.0 & -38.1 & 22.7 & -80.5 \\
\hline 4 & 67.1 & 13.4 & 69.2 & 97.1 & 168.7 & 38.6 & 239.8 & 63.1 \\
\hline 5 & 30.1 & -55.1 & 40.5 & -30.4 & 70.4 & -15.1 & 101.5 & -12.9 \\
\hline 6 & 63.4 & 88.1 & 158.5 & 100.8 & 108.8 & 149.9 & 276.6 & 140.4 \\
\hline 7 & 178.6 & 89.0 & 150.8 & 92.9 & 88.9 & 144.9 & 329.9 & 125.3 \\
\hline 8 & 120.2 & 130.2 & 170.3 & 140.7 & 203.2 & 162.2 & 298.7 & 210.2 \\
\hline 9 & 130.0 & 110.8 & 168.1 & 131.7 & 188.2 & 201.3 & 320.4 & 205.4 \\
\hline
\end{tabular}




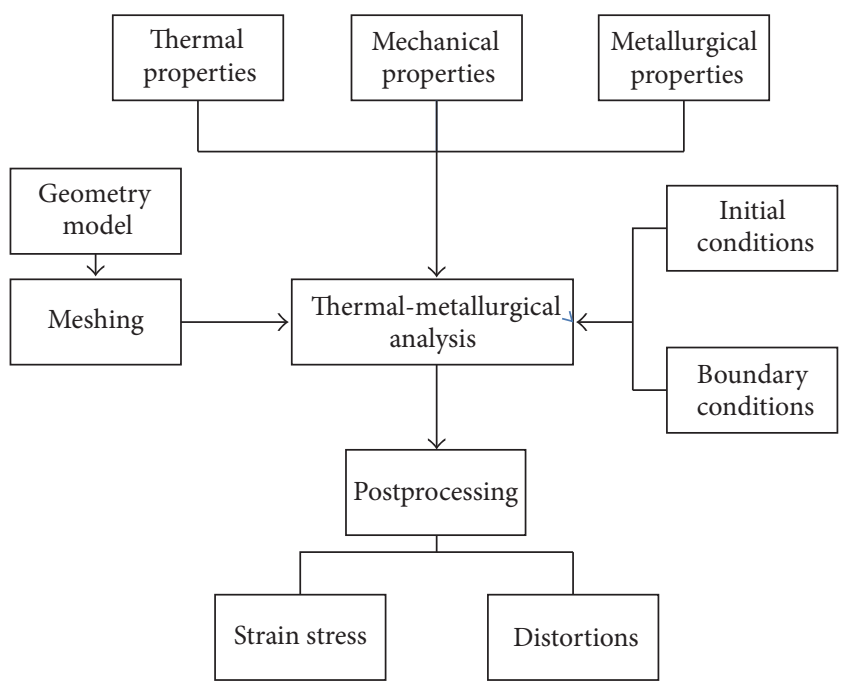

FIGURE 8: Flowchart of the welding simulation procedure.
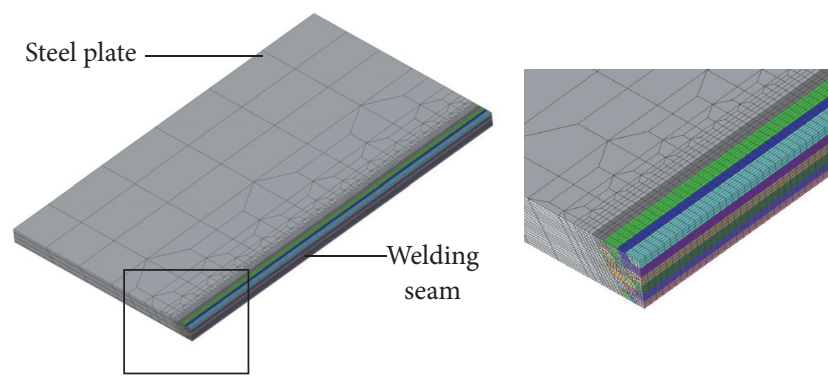

Figure 9: 3D finite element model of $75 \mathrm{~mm}$ wide welding seam.

section, the resultant force acting on the cross section equals zero. However, the measured residual stress implied that the section was under tension. The reason might be that compressive stress existed along the thickness direction of the cross section, and the hole-drilling method can only measure the residual stress on the surface of the section.

\section{Finite Element Simulation}

The commercial code SYSWELD was used to simulate the welding process of the butt weld. This software was specifically developed for the thermomechanical analysis of welding and heat treatment [15]. It typically contained three steps (modeling, analysis, and postprocessing) in welding simulation (Figure 8). Material, geometry, and heat source fitting were in the first step of the weld simulation [16].

For Q345qD steel, material database is contained in SYSWELD software material library. A sequentially coupled thermomechanical analysis was performed. After heat transfer analysis, structural analysis was carried out.

4.1. Meshing. Four 3D finite element models with different weld widths were developed. Considering the welding seam was symmetrically along the axis, only half of the welding seam was built as shown in Figure 9.

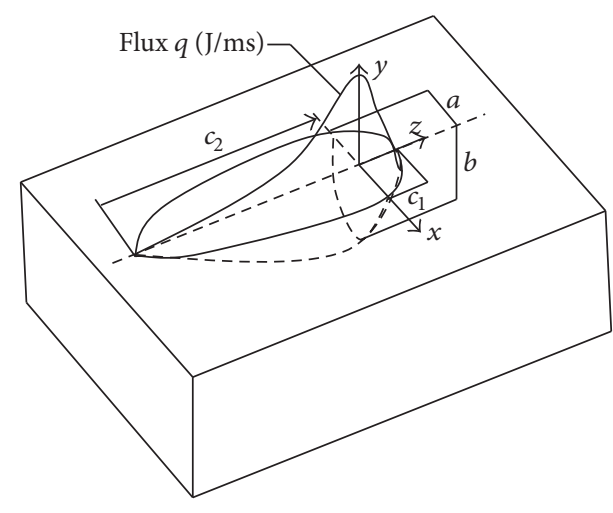

FIgURE 10: Double-ellipsoid heat source.

The element of eight-node hexahedron was adopted in the model meshing. High temperature and flux gradients are different in the fusion zone (FZ) and heat affected zone (HAZ); therefore the meshing size is different. Table 3 shows the element size.

4.2. Heat Source Modeling. To simulate the actual welding process, the double-ellipsoid heat source was adopted. The double-ellipsoid model was developed on a basis of the theory by Goldak et al. [17]. The heat source was as an internal heat source load applied on the model. The parameters of the depth direction were added in the source. Welding heat source is moving at a predefined speed in the welding direction on weld trajectory. The heat flux function was defined as follows:

$$
\begin{aligned}
& q(x, y, z, t)=\frac{6 \sqrt{3} Q \mathrm{Qff}}{a b c_{1} \pi \sqrt{\pi}} e^{-3\left(x^{2} / a^{2}+y^{2} / b^{2}+(z-v t)^{2} / c_{1}{ }^{2}\right)}, \\
& q(x, y, z, t)=\frac{6 \sqrt{3} \mathrm{Qfr}}{a b c_{2} \pi \sqrt{\pi}} e^{-3\left(x^{2} / a^{2}+y^{2} / b^{2}+(z-v t)^{2} / c_{2}{ }^{2}\right),}
\end{aligned}
$$

where $Q$ is the power input from the welding source; ff and $\mathrm{fr}$ are the fractions of heat deposited in either region $(\mathrm{ff}+\mathrm{fr}$ $=2$, and $\mathrm{ff}$ and fr are, respectively, 0.6 and 1.4); $a, b, c_{1}$, and $c_{2}$ denote the dimensions of the heat source. Figure 10 shows the configuration of the double-ellipsoid heat source.

4.3. Phase Transformation. The influence of phase transformation on the residual stress induced by the welding process should be considered [18]. For the purpose of simulating the phase transformation during the welding process, the metallurgical analysis was performed based on the phase transformation laws [19]. The phase transformations involved diffusion for steels, such as austenitic, ferritic-perlitic, and bainitic transformations. Johnson-Mehl-Avrami law [20] was adopted under isothermal conditions:

$$
p(T, t)=\bar{p}(T)\left(1-\exp \left(-\left(\frac{t}{\tau_{R}(T)}\right) n^{(T)}\right)\right),
$$

where $\bar{p}$ is the phase proportion obtained after an infinite time at temperature $T ; \tau_{R}$ is the delay time; $n$ represents the exponent associated with the reaction speed. 
TABLE 3: Element sizes.

\begin{tabular}{|c|c|c|c|c|c|}
\hline Widths (mm) & Qty. of welds & $\begin{array}{c}\text { Sizes of the element } \\
\text { near FZ }\left(\mathrm{mm}^{3}\right)\end{array}$ & $\begin{array}{c}\text { Sizes of other } \\
\text { elements }\left(\mathrm{mm}^{3}\right)\end{array}$ & $\begin{array}{c}\text { Qty. of } \\
\text { elements }\end{array}$ & Qty. of nodes \\
\hline 45 & 12 & $2 \times 2 \times 2$ & $50 \times 50 \times 5$ & 49668 & 51472 \\
\hline 55 & 14 & $2 \times 2 \times 2$ & $50 \times 50 \times 5$ & 53628 & 55273 \\
\hline 65 & 19 & $2 \times 2 \times 2$ & $50 \times 50 \times 5$ & 66408 & 68124 \\
\hline 75 & 23 & $2 \times 2 \times 2$ & $50 \times 50 \times 5$ & 70348 & 72649 \\
\hline
\end{tabular}
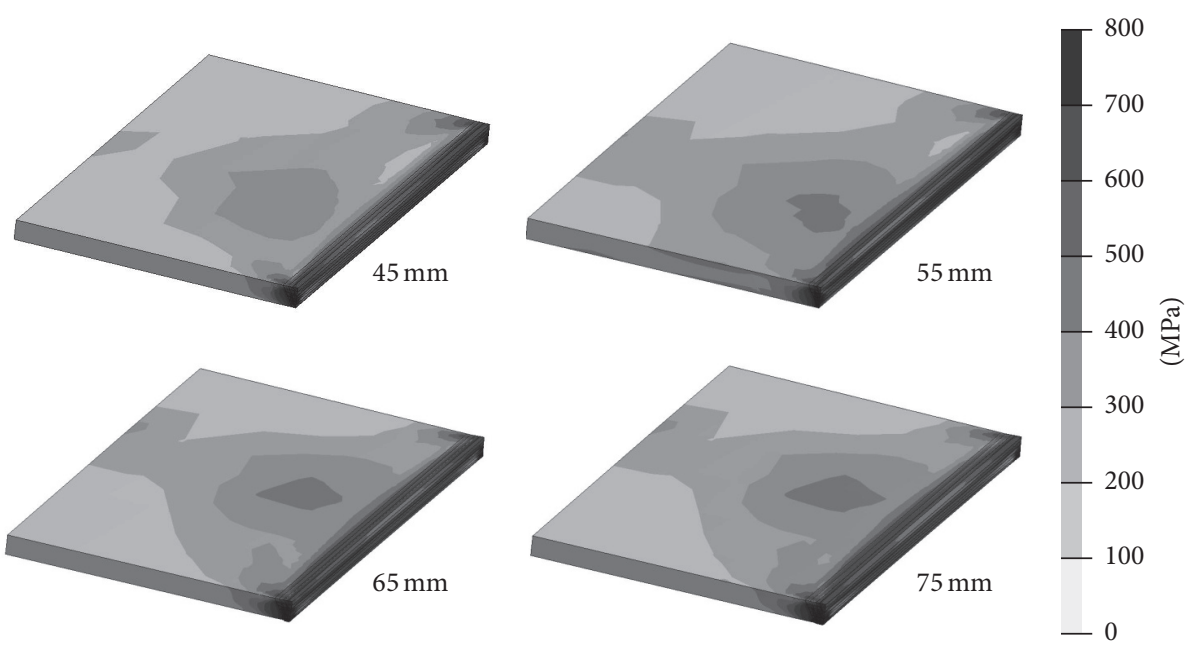

FIGURE 11: von-Mises stress.

The martensitic transformations were described by using the Koistinen-Marburger law [20]:

$$
\begin{aligned}
& p(T, t)=\bar{p}(T)\left(1-\exp \left(-b\left(M_{s}-T\right)\right)\right) \\
& \text { with } T \leq M_{s} \text {, }
\end{aligned}
$$

where $\overline{p_{m}}$ is the phase proportion obtained at an infinitely low temperature ( $\overline{p_{m}}$ is frequently assimilated to 1$) ; M_{s}$ and $b$, respectively, describe the initial transformation temperature and the evolution of the transformation process according to temperature.

4.4. Initial and Boundary Conditions. The welding process was conducted at the construction plant, so the initial temperature was the atmospheric temperature, $20^{\circ} \mathrm{C}$. Thermal convective and radiation losses of the model were taken into account. The rigid clamping was applied on the ends. These boundary conditions were applied to the model by specifying the value of combined heat transfer coefficient and the surrounding temperatures to the surface. All the mechanical and physical material properties were temperature-dependent.

4.5. Results. The von-Mises stresses of the seams with different widths are shown in Figure 11. Simulation results of the longitudinal and transverse residual stress are shown in Figures 12 and 13. The residual stress is approximately symmetric by the middle line of the steel plate. The maximum residual stress occurs in the locations near the weld fusion line. The distribution of the four different width welds is almost similar. The residual stress increases with the increase of the width of the butt welds.

4.6. Validations and Discussions. The obtained residual stresses obtained from the FE simulation are compared with the measured values in Table 4. At Point 1, the transversal residual stress and the longitudinal residual stress in the simulation results are, respectively, $3.9 \%$ and $16.9 \%$ lower than corresponding values in the testing results. According to the simulation and measurement results, the distribution of the residual stress of wide butt welding seams is similar to that of the normal wide butt seam. The residual stress data obtained by the hole-drilling method proved the distribution rule of the residual stress in wide butt welds. Particularly, the transverse residual stress errors between the simulation and measurement results are a little larger than the longitudinal residual stress errors. The errors of the two residual stresses are within the margin of error.

The magnitude and distribution of residual stress in the wide butt welds have significant influences on the fatigue behaviors of the steel truss bridge [1]. Therefore, the residual stress induced by the change in the welding width should be emphasized. Experimental results proved the existence of high residual stress during the welding process of wide butt welding seams, and the comparisons of the residual stresses of the welds with different widths (Figure 3) are shown in Figures 6 and 7. When the width is $75 \mathrm{~mm}$, the stress is about $341.5 \mathrm{MPa}$, which is close to the yield strength of the steel. The maximum longitudinal residual stress in these welds is 


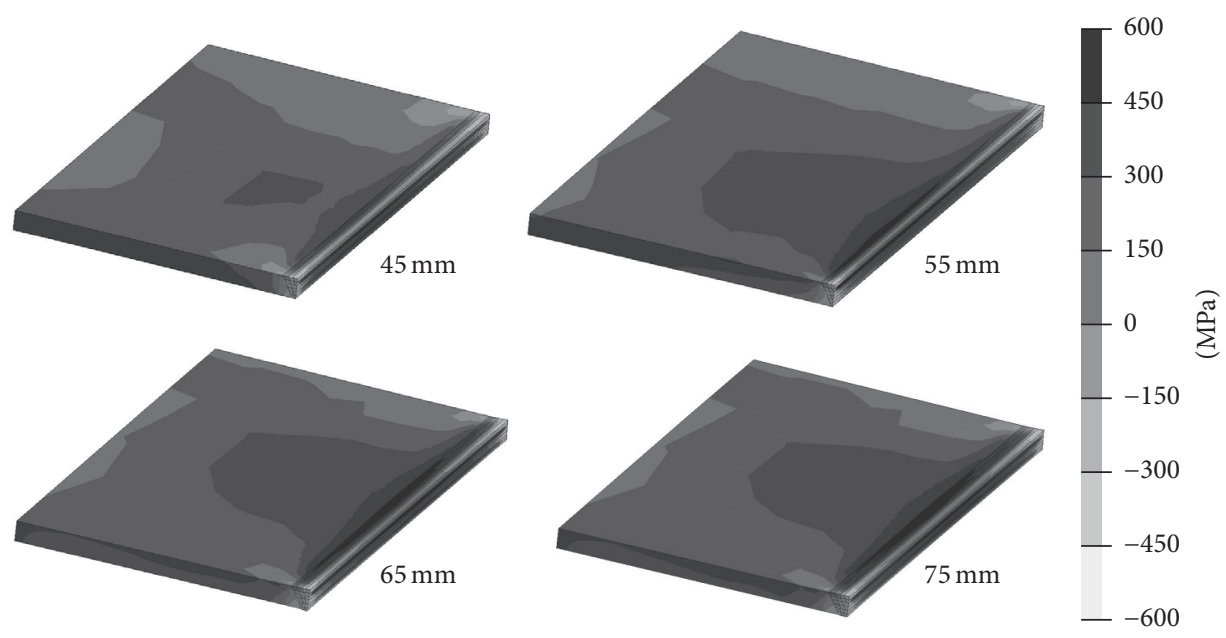

Figure 12: Transverse residual stress.

TABLE 4: Simulation results.

\begin{tabular}{|c|c|c|c|c|c|c|}
\hline \multirow{2}{*}{$\begin{array}{l}\text { Weld width } \\
(\mathrm{mm})\end{array}$} & \multicolumn{3}{|c|}{ Transverse residual stress of location 1} & \multicolumn{3}{|c|}{ Longitudinal residual stress of location 1} \\
\hline & Test $(\mathrm{MPa})$ & Prediction $(\mathrm{MPa})$ & $\begin{array}{c}\text { Test-to-prediction } \\
\text { ratio }\end{array}$ & Test $(\mathrm{MPa})$ & $\begin{array}{l}\text { Prediction } \\
(\mathrm{MPa})\end{array}$ & $\begin{array}{c}\text { Test-to-prediction } \\
\text { ratio }\end{array}$ \\
\hline 45 & 129.3 & 110.6 & 1.17 & 156.4 & 150.5 & 1.04 \\
\hline 55 & 161.5 & 148.7 & 1.09 & 194.1 & 201.2 & 0.96 \\
\hline 65 & 194.9 & 190.2 & 1.02 & 271.1 & 264.3 & 1.03 \\
\hline 75 & 224.8 & 225.8 & 0.99 & 341.5 & 330.1 & 1.03 \\
\hline Mean & & & 1.07 & & & 1.02 \\
\hline Cov & & & 0.07 & & & 0.03 \\
\hline
\end{tabular}

achieved at Point 1 (Figure 6). The residual stress decreases as the measuring point locates far away from the weld. The residual stress falls to $0 \mathrm{MPa}$ when the distance increases to about $85 \mathrm{~mm}$. The distribution is that the residual stress appears to be compressive stress and alternates into tensile stress from a certain distance. The distribution pattern of the residual stress is consistent with the pattern of the typical butt weld. Moreover, while the pattern is similar across different welding widths (Figure 14), the strength of the residual stress increases when the width of the welds increases. In order to ensure the reliability of the welding seams under the fatigue loads or other vibration environments, the weld is usually controlled within a certain small width. However, if the width of butt welds is out of control and beyond this specified value, additional measures are required to minimize the residual stress within a satisfactory level.

\section{Experimental Studies on Reductions of Residual Stress}

The experimental and numerical studies showed that the welding process in wide butt weld produced significant residual stress. This section aims to experimentally study the effective ways to minimize the residual stress.
5.1. Ultrasonic Peening Method. Various methods can eliminate residual stress, such as heat treatment, mechanical method, the explosion method, vibration aging, vibration welding, and ultrasonic peening [21]. The environmental requirement of the ultrasonic impacting method is not quite strict and it has been widely used to eliminate residual stress of the construction plant. Therefore, the ultrasonic impacting device (WD2050) with the impact frequency of $20 \mathrm{kHz}$ and amplitude of $50 \mu \mathrm{m}$ was adopted in our experiment (Figure 15). Meanwhile, the impression coverage ratio was greater than $90 \%$, the impact curve depths beside the weld joint and the base metal were, respectively, $(0.8 \pm 0.2) \mathrm{mm}$ and $(0.5 \pm 0.2) \mathrm{mm}$ and the impacting speed was $200 \mathrm{~mm} / \mathrm{min}$. Before impacting the weld, we cleaned the target locations on each surface of the hole-drilling regions. Then the residual stress was measured with the blind hole-drilling method.

5.2. Residual Stress after Ultrasonic Peening. Experimental results indicated that residual stresses were decreased by $17 \% \sim 43 \%$ after ultrasonic peening treating. For comparison, the maximum transversal residual stress and longitudinal residual stress before and after the ultrasonic peening are listed in Table 5. It shows that after the ultrasonic peening the longitudinal residual stresses of the four different butt 
TABLE 5: Residual stress relief ratio.

\begin{tabular}{|c|c|c|c|c|c|c|}
\hline \multirow{2}{*}{$\begin{array}{l}\text { Weld width } \\
(\mathrm{mm})\end{array}$} & \multicolumn{3}{|c|}{ Transverse residual stress of location 1} & \multicolumn{3}{|c|}{ Longitudinal residual stress of location 1} \\
\hline & $\begin{array}{c}\text { Test before } \\
\text { relieving }(\mathrm{MPa})\end{array}$ & $\begin{array}{c}\text { Test after } \\
\text { relieving }(\mathrm{MPa})\end{array}$ & Relief ratio & $\begin{array}{c}\text { Test before } \\
\text { relieving }(\mathrm{MPa})\end{array}$ & $\begin{array}{l}\text { Test after relieving } \\
(\mathrm{MPa})\end{array}$ & Relief ratio \\
\hline 45 & 129.3 & 107.1 & 1.17 & 156.4 & 124.2 & 1.21 \\
\hline 55 & 161.5 & 126.9 & 1.21 & 194.1 & 110.1 & 1.43 \\
\hline 65 & 194.9 & 154.2 & 1.21 & 271.1 & 224.6 & 1.17 \\
\hline 75 & 224.8 & 160.9 & 1.28 & 341.5 & 229.5 & 1.33 \\
\hline Mean & & & 1.22 & & & 1.28 \\
\hline Cov & & & 0.04 & & & 0.09 \\
\hline
\end{tabular}
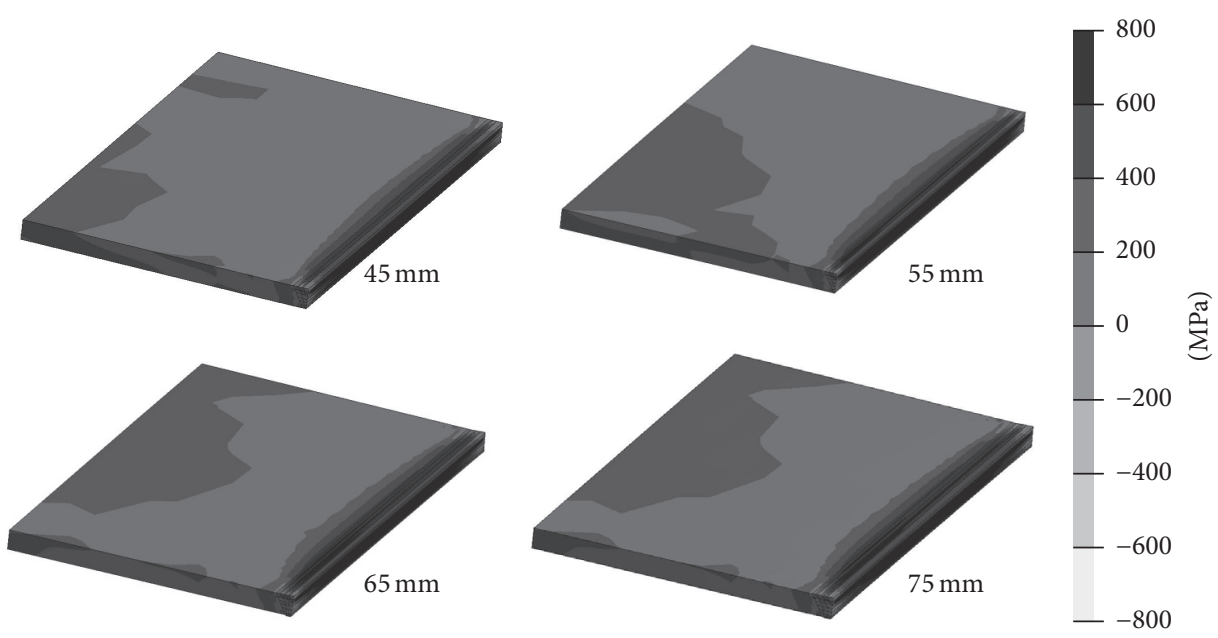

FIGURE 13: Longitudinal residual stress.

welds were reduced by $21 \%, 43 \%, 17 \%$, and $33 \%$, respectively. For example, the maximum longitudinal residual stress of the $75 \mathrm{~mm}$ wide welding seam was decreased from $341.5 \mathrm{MPa}$ to $229.5 \mathrm{MPa}$. Meanwhile, the transverse residual stresses for the butt welds were decreased by $17 \%, 21 \%, 21 \%$, and $28 \%$, respectively. For instance, the maximum transverse residual stress was decreased from $224.8 \mathrm{MPa}$ to $160.9 \mathrm{MPa}$. The explanation for these reductions is that the ultrasonic peening method can impact the steel surfaces that redistribute the residual stress from the high stress region to the low stress region. Thus, the compressive stress and tensile residual stress would compensate the results in the reduction of the residual stress around the butt welds. The comparisons in Table 5 also showed that the residual stresses in transverse and longitudinal direction to the weld seam were averagely decreased by $22 \%$ and $28.4 \%$, respectively. These comparisons confirmed that the ultrasonic peening method was effective in reducing the residual stress around the wide butt weld.

\section{Conclusions}

This paper studied the residual stress of wide butt welds in the steel truss members. The blind-hole method was adopted to measure the residual stress in wide butt welds during the construction of a steel bridge. Numerical analysis of the welding process was also carried out by general commercial

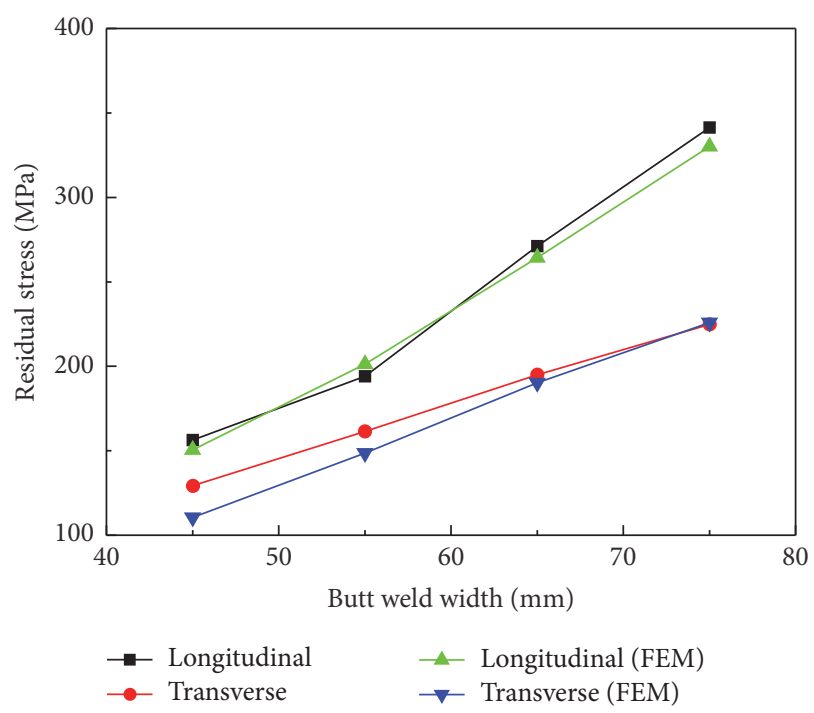

FIGURE 14: Comparison of the residual stresses of different seam widths.

software SYSWELD. Ultrasonic peening method was used to reduce the residual stress. Based on these experimental and numerical studies, some conclusions were drawn as follows. 


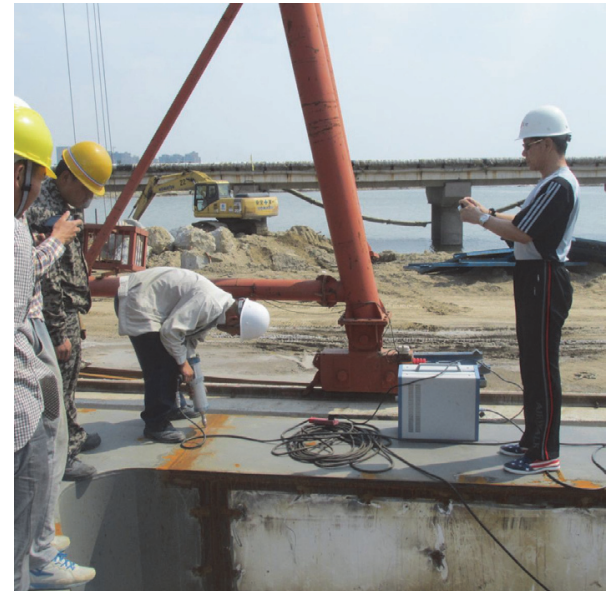

FIGURE 15: Ultrasonic peening method.

Firstly, experimental results indicated that the magnitude of residual stress increased with the increase in the width of the welding seam. Meanwhile, the residual stress firstly appeared to be compressive and then transferred to be tensile as the distance to the butt welds increases.

Secondly, the developed FE models could be used to simulate the residual stress produced by the wide butt welding in the site construction. The comparisons with the experimental results show that the FE model averagely underestimates the residual stress in transverse and longitudinal direction to the welding seam by $7 \%$ and $2 \%$, respectively.

Thirdly, the experimental studies showed that ultrasonic peening method could be used to reduce the residual stress in the wide butt welds. For the four butt welds in the experiments, using the ultrasonic peening method, the residual stresses in the transverse and longitudinal direction to the welding seam were averagely reduced by $22 \%$ and $28 \%$, respectively.

\section{Competing Interests}

The authors declare no conflict of interests.

\section{References}

[1] Y. Ding, Principles of Steel Structure Design, Press of Tianjin University, Tianjin, China, 2004 (Chinese).

[2] China Standard, "Code for the design of steel structures," GB 50017-2003, China Standard Press, 2003 (Chinese).

[3] "Code for welding ofsteel structures," GB 50661-2011, China Standard Press, 2011 (Chinese).

[4] X. P. Zhang and N. Wang, "Measurement of welding residual stress in the heavy converter using blind-hole method," Mechanics in Engineering, vol. 29, no. 3, pp. 45-49, 2007.

[5] Z. L. Zhou, M. Xie, and J. Q. Jiao, "Investigation of welding residual stress in the integrative linking part of Yangzi River Bridge," Journal of Dalian Railway Institute, vol. 19, no. 3, pp. 79-84, 1998.
[6] S.-Z. Tian and F.-C. Li, "A method for testing residual weld stress in beam and plane components," Journal of Harbin Engineering University, vol. 20, no. 5, pp. 501-507, 2009.

[7] N. Wang, Researchon Measuring Welding Residual Stressof Plateof Moderate Thickness Using Blind-hole Method, Dalian Technology University, Dalian, China, 2007 (Chinese).

[8] Y.-H. Huang, R.-H. Wang, and Q. Gan, "Experiment on welding residual stress of integral joint for steel truss bridge," Zhongguo Gonglu Xuebao/China Journal of Highway and Transport, vol. 24, no. 1, pp. 83-88, 2011.

[9] Y.-B. Wang, G.-Q. Li, and S.-W. Chen, "Residual stresses in welded flame-cut high strength steel H-sections," Journal of Constructional Steel Research, vol. 79, pp. 159-165, 2012.

[10] Y.-B. Wang, G.-Q. Li, and S.-W. Chen, "The assessment of residual stresses in welded high strength steel box sections," Journal of Constructional Steel Research, vol. 76, pp. 93-99, 2012.

[11] Y. Pei, Y. F. Bao, and N. Y. Tang, "Effect of boundary and distance between holes on accuracy of blind-hole technique," Welding Institution, vol. 15, no. 3, pp. 191-195, 1994.

[12] ASTM, "Standard test methods and definitions for mechanical testing of steel products," ASTM A370-13, American Society for Testing and Materials, 2013.

[13] ASTM, "Standard test method for determining residual stresses by the hole-drilling strain-gage method," ASTM E837-08, American Society for Testing and Materials, 2008.

[14] CB 3395-92, Test Method for Determining Residual Stresses-HoleDrillingmethod, China State Shipbuilding Corporation, Beijing, China, 1992 (Chinese).

[15] C. Heinze, A. Pittner, M. Rethmeier, and S. S. Babu, "Dependency of martensite start temperature on prior austenite grain size and its influence on welding-induced residual stresses," Computational Materials Science, vol. 69, pp. 251-260, 2013.

[16] M. Zubairuddin, S. K. Albert, S. Mahadevan, M. Vasudevan, V. Chaudhari, and V. K. Suri, "Experimental and finite element analysis of residual stress and distortion in GTA welding of modified 9Cr-1Mo steel," Journal of Mechanical Science and Technology, vol. 28, no. 12, pp. 5095-5105, 2014.

[17] J. Goldak, A. Chakravarti, and M. Bibby, "A new finite element model for welding heat sources," Metallurgical Transactions B, vol. 15, no. 2, pp. 299-305, 1984.

[18] P. Ferro, H. Porzner, A. Tiziani, and F. Bonollo, "The influence of phase transformations on residual stresses induced by the welding process-3D and 2D numerical models," Modelling and Simulation in Materials Science and Engineering, vol. 14, no. 2, pp. 117-136, 2006.

[19] D. P. Koistinen and R. E. Marburger, "A general equation prescribing the extent of the austenite-martensite transformation in pure iron-carbon alloys and plain carbon steels," Acta Metallurgica, vol. 7, no. 1, pp. 59-60, 1959.

[20] S. A. Tsirkas, P. Papanikos, and T. Kermanidis, "Numerical simulation of the laser welding process in butt-joint specimens," Journal of Materials Processing Technology, vol. 134, no. 1, pp. 59-69, 2003.

[21] Y. N. Zhao, Z. N. Zhang, and L. G. Jia, "General research situation of residual stress," Steel Engineering Research, vol. 17, no. 1, pp. 195-201, 2012. 

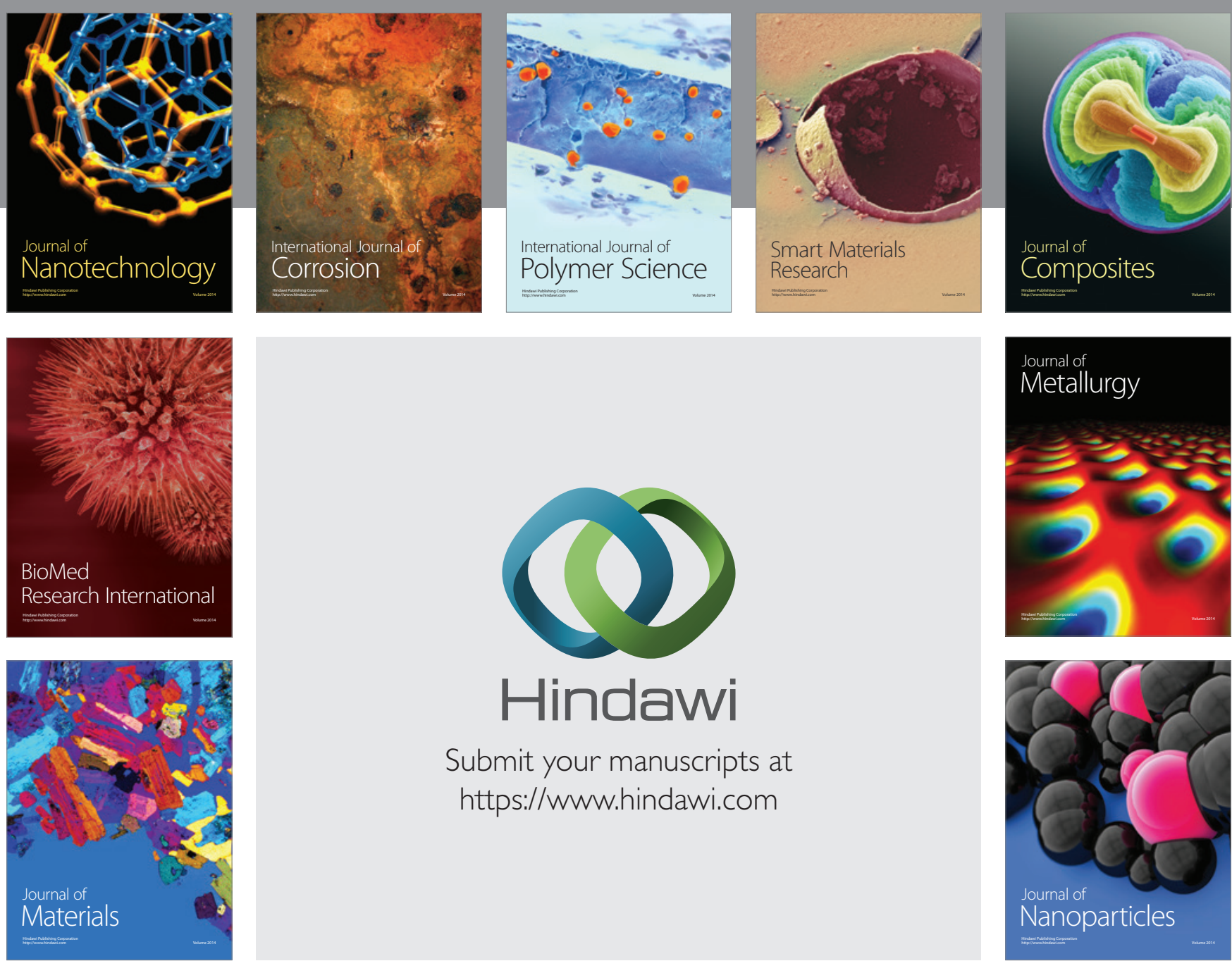

\section{Hindawi}

Submit your manuscripts at

https://www.hindawi.com

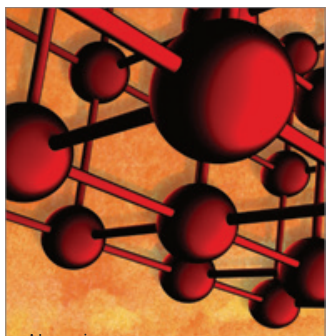

Materials Science and Engineering
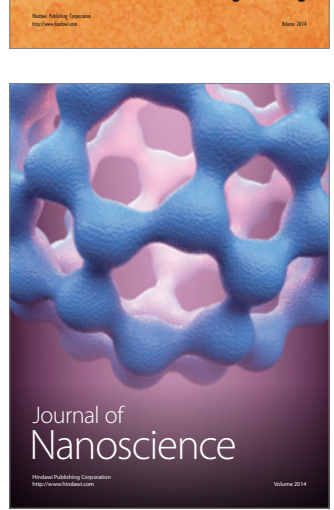
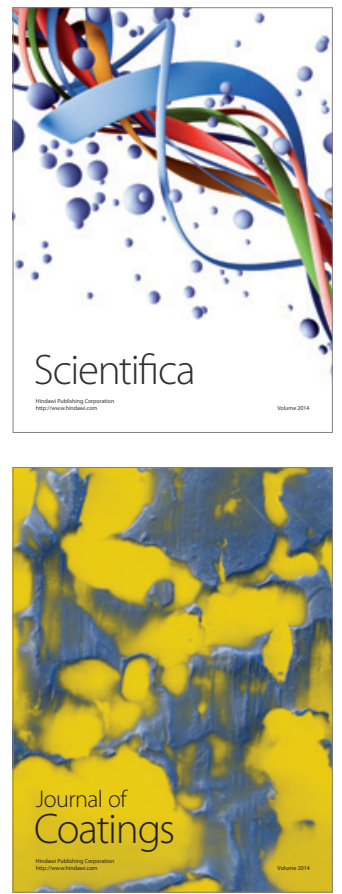
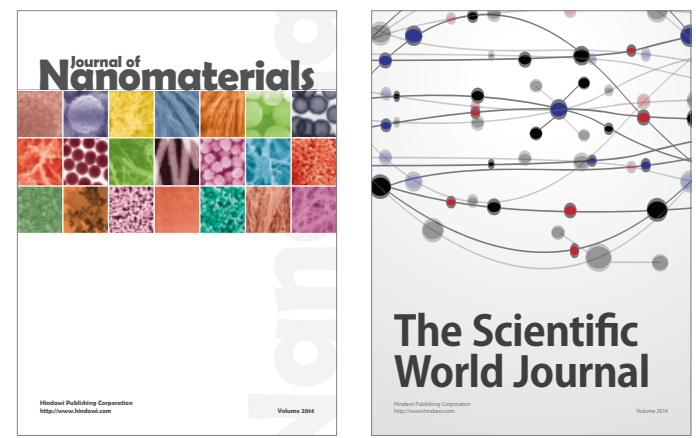

The Scientific World Journal
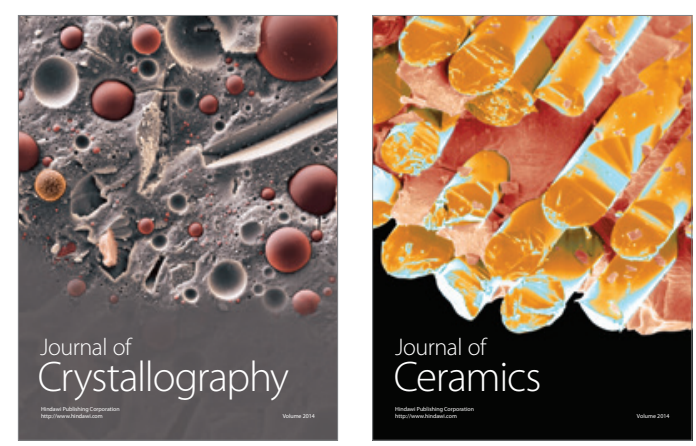
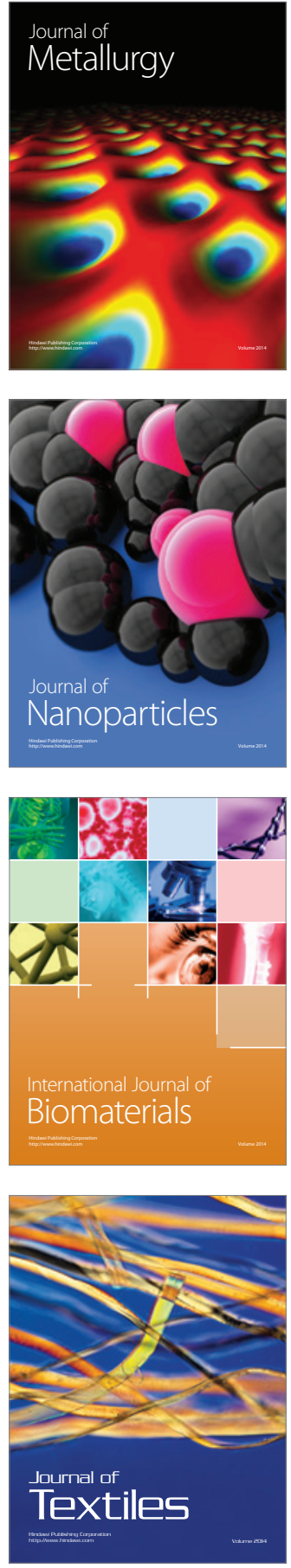